\title{
Existence of homoclinic solutions for the non-autonomous fractional Hamiltonian systems
}

\author{
Hamid Boulares ${ }^{1}$ and Fathi Khelifi ${ }^{2}$ \\ ${ }^{1}$ Université 8 Mai 1945 Guelma Faculté des Mathématiques et de l'Informatique et des \\ Sciences de la Matière \\ ${ }^{2}$ University of Hail College of Sciences
}

April 28, 2020

\begin{abstract}
In this reseach work, we give a new result to guarantee the existence of homoclinic solutions for the nonperiodic fractional Hamiltonian systems -_ $\{\mathrm{t}\} \mathrm{D}_{-}\{[?]\}^{\wedge}\{\alpha\}\left({ }_{-}\{-[?]\} \mathrm{D}_{-}\{\mathrm{t}\}^{\wedge}\{\alpha\} \mathrm{x}(\mathrm{t})\right)-\mathrm{L}(\mathrm{t}) \mathrm{x}(\mathrm{t})+[?] \mathrm{W}(\mathrm{t}, \mathrm{x}(\mathrm{t}))=0$, where $\alpha[?](1 / 2,1], \mathrm{x}[?] \mathrm{H}^{\wedge}\{\alpha\}\left(\mathrm{R}, \mathrm{R}^{\wedge}\{\mathrm{N}\}\right)$, $\mathrm{W}[?] \mathrm{C}^{\mathbf{1}}\left(\mathrm{R} \times \mathrm{R}^{\wedge}\{\mathrm{N}\}, \mathrm{R}\right)$. We assume that $\mathrm{W}(\mathrm{t}, \mathrm{x})$ do not satisfy the global Ambrosetti-Rabinowitz condition and is not necessary periodic in $t$. This result generalizes and improves some existing results in the literature.
\end{abstract}

\section{Hosted file}

Fathi CHamid- swp.pdf available at https://authorea.com/users/308982/articles/439997-existenceof-homoclinic-solutions-for-the-non-autonomous-fractional-hamiltonian-systems 